\title{
ASSESSMENT OF STUDENTS' ATTITUDE TOWARDS LEARNING COMMUNICATION SKILLS: AN EXPLORATORY STUDY
}

\author{
Rupam Tripathi, ${ }^{1}$ Navin Tripathi, ${ }^{2}$ Malati Tripathi, ${ }^{3}$ Rubina Shrestha, ${ }^{4}$ Dheeraj Kesari, ${ }^{5}$ Pradip Chhetri ${ }^{4}$
}

ABSTRACT

\section{INTRODUCTION}

Good communication skills can increase the health-care providers' diagnostic efficiency and decision making ability, as well as lead to improved patient satisfaction. The aim of this study is to determine the attitude associated with learning communication skills among dental and medical students.

\section{MATERIAL AND METHODS}

A descriptive study was conducted among 231 students, studying in Universal College Of Medical Sciences (UCMS), College of Dental Surgery, Bhairahawa, Nepal using a standardized pro forma which consisted of questions on general information and of communication skills using validated Communication Skills Attitude Scale. For statistical analysis, Mann-Whitney U test and Kruskal-Wallis test were applied.

\section{RESULTS}

Students indicate high levels of positive attitudes and low levels of negative attitudes. Attitudinal scores differ insignificantly in relation to gender.

\section{CONCLUSION}

Medical and dental students in our study show basically a positive approach. Further investigation is necessary to explore and understand attitudes towards communication skills of medical and dental undergraduates.

KEYWORDS Attitude, communication skills, medical and dental students, undergraduates

1. Department of Conservative Dentistry and Endodontics, UCMS, College of Dental Surgery, Bhairahawa,Nepal

2. Department of Orthopaedics and Trauma Surgery, Gandaki Medical College, Pokhara, Nepal

3. Department of Gynaecology and obstetrics, Gandaki Medical College, Pokhara, Nepal

4. Department of Community Medicine, Universal College of Medical Sciences, Bhairahawa, Nepal

5. Department of Anaesthesiology, UCMS, College of Dental Surgery, Bhairahawa, Nepal

DOI: https://doi.org/10.3126/jucms.v7i1.24690

\author{
For Correspondence \\ Dr. Rupam Tripathi \\ Department of Conservative Dentistry and Endodontics \\ Universal college of Medical Sciences, College of Dental Surgery \\ Bhairahawa, Nepal \\ Email:rupam.tripathi121@yahoo.com
}




\section{INTRODUCTION}

Good communication skills are essential for effective clinical practice in medical and dental field. An ability to communicate effectively with patients in particular, to use active listening skills, to handle patient emotions sensitively, and to demonstrate empathy and professionalism is crucial. ${ }^{1}$

Traditional teaching imparts students with theoretical and practical knowledge of diseases processes and gives them education about diagnostic and treatment modalities, but does not address communication skills which are most essential in dealing with patients. ${ }^{2,3}$ However, over the past years, requirement of communication skills in the dental and medical curriculum have received a considerable amount of attention among scholars in Nepal.

Literature shows a number of studies on the attitude of medical students toward learning communication skills in the Nepal but does not include reports of any evaluation among dental students. So, this study was done to assess the attitude of both medical and dental students towards learning communication skills .

\section{MATERIAL AND METHODS}

A prospective study was conducted among 231 dental and medical students of Universal College Of Medical Sciences (UCMS), College of Dental surgery, Bhairahawa, Nepal for the duration of 2 months from October, 2018 to November, 2018. Ethical approval was obtained from the Institutional Ethical Review Board of UCMS and permissions for the study were sought from the head of the institutions before commencing the study. Complete enumeration survey was done. Final years and interns who were exposed to the clinical postings were included in the present study. $1^{\text {st }}, 2^{\text {nd }}$ and $3^{\text {rd }}$ years students were excluded from the study. Informed consent was obtained from the students by disclosing the purpose of the study and questionnaire was distributed to them.

The questionnaire had two parts. The first part included demographic details and second part consisted of 26 questions of communication skills using validated Communication Skills Attitude Scale. The Communication Skills Attitudes Scale (CSAS) created by Rees, Sheard and Davies and published in 2002 has been a widely used instrument for measuring medical students' attitudes towards learning communication skills. The CSAS addresses teaching and learning of communication skills most specifically and has been most widely used and validated. The CSAS contains 26 statements concerning attitudes towards learning communication skills. CSAS (previously twenty-six items) with two subscales: Positive Attitude Subscale (PAS) and
Negative Attitude Subscale (NAS). Thirteen statements are positively worded (e.g.: "In order to be a good doctor I must have good communication skills" item 1) and thirteen negatively (e.g.: "I don't need good communication skills to be a doctor" item19). In the study, the Positive Attitude Scale's internal consistency measured with Cronbach's alpha was 0.87, and the Negative Attitude Scale's Cronbach's alpha was 0.65.Two scores are determined from the adapted CSAS: the mean PAS and NAS scores.

These were achieved by summing the scores of the thirteen PAS and thirteen NAS items, respectively, and dividing them by the number of items in each scale. Each statement is followed by five boxes in a Likert-like consecutive order, named "Strongly disagree", "Disagree", "Neutral", "Agree" and "Strongly agree" and is numbered from 1 to 5 respectively. The informant is asked to check one box only. Each item was scored from 1 to 5 according to the box that had been checked in the questionnaires.

The data was entered manually on Microsoft excel (MS Office Excel 2000; Microsoft Corporation, Redmond, WA, USA), checked for possible data entry errors. The data were analyzed using SPSS version 20.0 (IBM Corp. Armonk, NY: IBM Corp) for generation of descriptive, as well as inferential statistics. Data were not normally distributed so, the statistical significant difference among groups was determined by the Mann-Whitney U test and Kruskal-Wallis test.

\section{RESULTS}

Table 1 shows comparison of mean scores of attitude towards communication skills for subjects of different years of education which showed statistically no significant difference $(\mathrm{p}=0.121)$.

Table 1. Comparison of the scores within the respective year of study for CSAS

\begin{tabular}{llllll}
\hline \multicolumn{2}{c}{ Students } & n-231 & $\begin{array}{l}\text { Mean } \\
\text { Score }\end{array}$ & Df & p-value \\
\hline BDS & final yr & 59 & 131.58 & & \\
& intern & 52 & 103.35 & & \\
\multirow{2}{*}{ MBBS } & final yr & 86 & 116.80 & 3 & 0.121 \\
& intern & 34 & 106.31 & & \\
\hline
\end{tabular}

Non-parametric statistics=Mann-Whitney Z statistics Significant level $=0.05$

Table 2 shows comparison of mean scores of attitude among gender in over all subjects. Statistically no significant difference was found among the gender overall $(\mathrm{p}=0.479)$. 
Table 2. Comparison of scores on items of communication skills among gender in over all subjects

\begin{tabular}{lllll}
\hline & Gender & Mean & \\
& & $\begin{array}{l}\text { Mear } \\
\text { score }\end{array}$ & p-value \\
\hline $\begin{array}{l}\text { Sum } \\
\text { score }\end{array}$ & Male & 111 & 112.29 & 0.479 \\
& Female & 120 & 118.50 & \\
\hline
\end{tabular}

Non parametric statistics $=$ Kruskal-Wallis test

\section{DISCUSSION}

The aim of the study is to assess the attitude of dental and medical undergraduates towards learning communication skills. Evidence from the literature has shown that good communication skills not only increase the health care providers' diagnostic efficiency and decision making ability but also improved patient satisfaction, greater adherence to provider recommendations, decreased anxiety, and lower rates of complaints and malpractice claims. ${ }^{4.8}$ The attitude of students toward communication skills may be important indicators of the importance they place on them, and they may eventually influence communication behaviors in clinical settings. Rees, Sheard and Davies published the communication skills Attitudes Scale (CSAS) in 2002, which measures students' attitudes towards learning communication skills during medical school. This scale has been already validated in several studies. ${ }^{911}$ So, this study used an adapted CSAS for both dental and medical students. Questionnare consists of both positive and negative items. Mean PAS was higher (53) and mean NAS was slightly lesser (35) in this study. Higher values for PAS suggest greater attitudes of medical and dental undergraduates for learning communication skills.

The attitude when assessed across both dental and medical students, final year students scored higher compared to intern . This may be due to the remarkable changes in internship, both personally and professionally. It has been well established that many interns have feelings of anxiety and depression at some point during the year. ${ }^{12-13}$ This may lead to decline in their attitudes towards learning communication skills. Studies have shown that negative mood that increased significantly during the internship is correlated negatively with empathic concern too. ${ }^{14}$ However, statistically no significant difference ( $>0.05)$ was found among all year of undergraduates.

In the present study, females scored higher in comparison to males in overall subjects. This is similar to studies reported to literature. ${ }^{15-16}$ This is may be due to high socialization of females than males. Females remain more attached with patients and have care giving attitudes than men. This suggestion is also supported by a study by Aspegren ${ }^{17}$ who found that male students did not regard communication skills learning as highly as their female counterparts and were slower in the learning process. However, this was in contrast to a study in Nepal on a group of medical students where no significant association was between gender and attitudes towards communication skills learning. ${ }^{18}$

\section{CONCLUSION}

Effectiveness of a communication skill training program could be improved if we had a greater understanding of the students' beliefs and attitudes toward doctor-patient communication. The present study found that both medical and dental students have positive attitudes towards communication skills learning. Therefore, good communications and counseling techniques can be taught and practiced to increase clinical competence in medical and dental schools.

\section{REFRENCES}

1. Hannah A, Millichamp CJ, Ayers KMS. A communication skills course for undergraduate dental students. J Dent Educ 2004; 68(9):970-7.

2. Yedidia MJ, Gillespie CC, Kachur E, Schwartz MD, Ockene J, Chepaitis AE, et al. Effect of communications training on medical student performance. JAMA. 2003;290:1157-65.

3. Joekes K, Noble LM, Kubacki AM, Potts HW, Lloyd M.Does the inclusion of 'professional development' teaching improve medical students' communication skills? BMC Med Educ. 2011 June 27;11:41. doi: 10.1186/1472-6920-11-41.

4. Van der Molen H, Klaver A, Duyx M. Effectiveness of a communication skills training program for the management of dental anxiety. Br Dent J 2004;196:101-7.

5. Huntington B, Kuhn N. Communication gaffes: a root cause of malpractice claims. Proc (Baylor Univ Med Cent) 2003;16: 157-61.

6. Evans B, Stanley R, Mestrovic R, Rose L. Effects of communication skills training on students' diagnostic efficiency. Med Educ1991;25:517-26.

7. Lanning SK, Ranson SL, Willett RM. Communication skills instruction utilizing interdisciplinary peer teachers: program development and student perceptions. J Dent Educ 2008;72 (2):172-82.

8. Irwin R, Richardson N. Patient-focused care: using the right tools. Chest 2006;130:73S-82S.

9. Rees C, Sheard C. The relationship between medical students' attitudes towards communication skills learning and their demographic and education-related characteristics. Med Educ. 2002;36:1017-1027. 
10. Rees C, Sheard C. Evaluating first-year medical students' attitudes to learning communication skills before and after a communication skills course. Med Teach. 2003;25:302-307.

11. Cleland J, Foster K, Moffat M. Undergraduate students' attitudes to communication skills learning differ depending on year of study and gender. Med Teach. 2005;27:246-251.

12. Kirsling RA, Kochar MS, Chan CH. An evaluation of mood states among first year residents. Psychol Rep.1989;65:355366.

13. Clark DC, Salazar-Grueso E, Grabler P, Fawcett J. Predictors of depression during the first 6 months on internship. Am J Psychiatry.1984;141:1095-1098.

14. Bellini LM, Baime M and Shea JA. Variation of mood and empathy during internship. JAMA. 2002; 287: 3143-3146.

15. Anvik T, Grimstad H, Baerheim A, et al. Medical students' cognitive and affective attitudes towards learning and using communication skills. A nationwide cross-sectional study. Med Teach. 2008;30:272.

16. Harlak H, Gemalmaz A, Gurel FS, 16.Dereboy C, Ertekin K. Communication skills training: Effects on attitudes toward communication skills and empathic tendency. Educ Health (Abingdon) 2008;21:62.

17. Aspegren K. BEME guide no. 2: teaching and learning communication skills in medicinea review with quality grading of articles. Med Teacher 1999;21:563-70.

18. Shankar RP, Dubey AK, Mishra P. Student attitudes towards communication skills training in medical college in western Nepal. Educ Health 2006;19:71-84. 